\title{
Results from Operational Testing of the Siemens Smart Grid-Capable Electric Vehicle Supply Equipment
}

\author{
Brion Bennett
}

May 2015

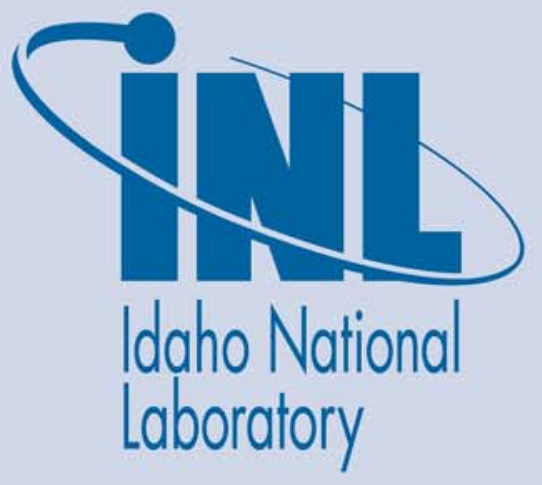

The INL is a U.S. Department of Energy National Laboratory operated by Battelle Energy Alliance 


\section{DISCLAIMER}

This information was prepared as an account of work sponsored by an agency of the U.S. Government. Neither the U.S. Government nor any agency thereof, nor any of their employees, makes any warranty, expressed or implied, or assumes any legal liability or responsibility for the accuracy, completeness, or usefulness, of any information, apparatus, product, or process disclosed, or represents that its use would not infringe privately owned rights. References herein to any specific commercial product, process, or service by trade name, trade mark, manufacturer, or otherwise, does not necessarily constitute or imply its endorsement, recommendation, or favoring by the U.S. Government or any agency thereof. The views and opinions of authors expressed herein do not necessarily state or reflect those of the U.S. Government or any agency thereof. 


\title{
Results from Operational Testing of the Siemens Smart Grid-Capable Electric Vehicle Supply Equipment
}

\author{
Brion Bennett
}

May 2015

Idaho National Laboratory Idaho Falls, Idaho 83415

http://www.avt.inel.gov

\author{
Prepared for the \\ U.S. Department of Energy \\ Office of Electricity Delivery and Energy Reliability \\ Under DOE Idaho Operations Office \\ Contract DE-AC07-05ID14517
}




\section{CONTENTS}

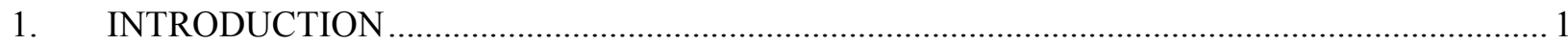

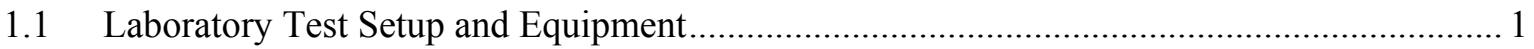

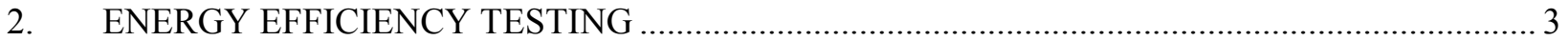

2.1 Electric Vehicle Supply Equipment Standby Power Consumption ................................... 4 子

2.2 Electric Vehicle Supply Equipment Efficiency …......................................................... 4

2.3 Electric Vehicle Supply Equipment Energy Measurement.................................................. 4

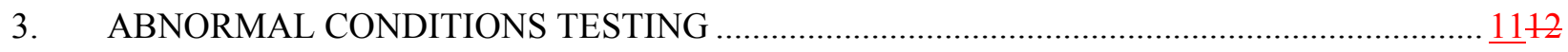

3.1 Electric Vehicle Supply Equipment Response to Abnormal Control Pilot Voltage .......... 1112

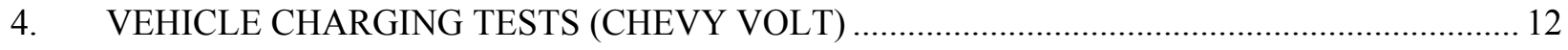

4.1 Electric Vehicle Supply Equipment Energy Efficiency …......................................... 1314

4.2 Electric Vehicle Supply Equipment Response to Interrupted Grid Power ...................... 1314

4.3 Electric Vehicle Supply Equipment Response to Curtailment of Grid Power..................... 14

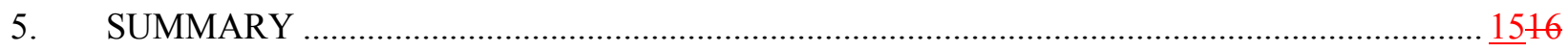

\section{FIGURES}

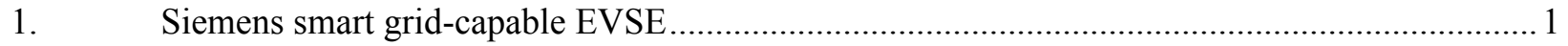

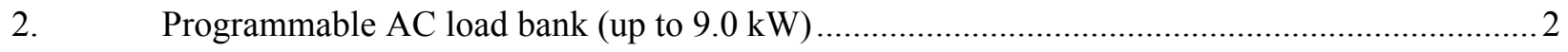

3. Hioki 3390 power meter and Eaton IQ 250 watt-hour meter with GE CTM-0C current

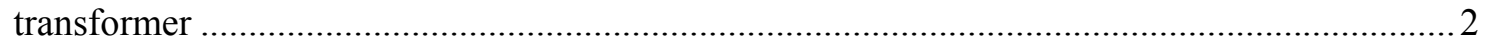

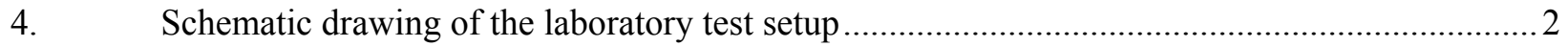

5. Schematic drawing of the 240-VAC single-phase test setup ................................................... 3

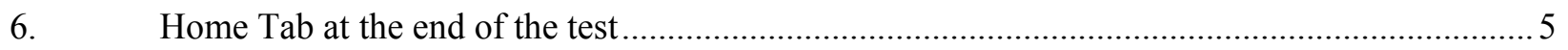

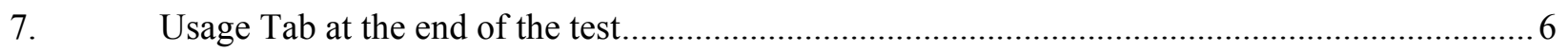

8. Home Tab 1.36-kWh, 240-V test shows $80 \%$ power, 23 Amps, and duration of test................ 7

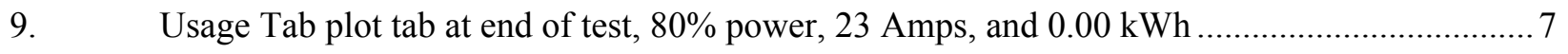


10. Screen shot of the Usage Tab after the conclusion of tests, showing $0.39 \mathrm{kWh}$ of energy ......... 8

11. Home Tab at the end of the 2.0-kwh test, showing 21 minutes elapsed time of test; the $\mathrm{kWh}$ of energy is 0.00 , but $\mathrm{kWh}$ of energy on the Usage Tab still incrementing up.

12. End-of-test $\mathrm{kWh}$ reading shows that a $0.20-\mathrm{kWh}$ of energy reading was pulled at $2: 42$

23; this was 23 minutes after test completion.

13. Screen shot of the Usage Tab after conclusion of 208-VAC testing and 240-VAC testing $\underline{1011}$

14. Energy measurement of 208-VAC test, showing the energy measurements for INL instrumentation and the EVSE Usage Tab

15. SAE J1772 (Version 2010)-recommended practice of control pilot voltage range for each state

16. EVSE tests using a 2012 Chevrolet Volt

17. Schematic drawing of the vehicle test setup.

18. EVSE response to grid interrupt. Error! Bookmark not defined. 15

19. EVSE response to the pause button 1516

\section{TABLES}

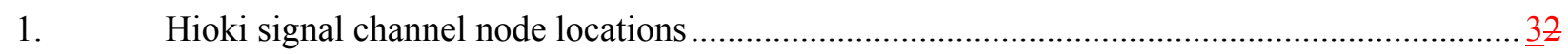

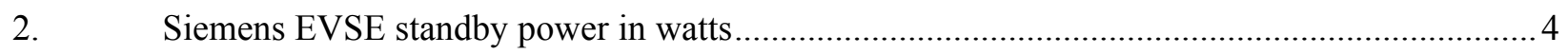

3. Siemens EVSE efficiency testing LED “OFF” WiFi "OFF” ............................................... 4

4. Siemens energy efficiency testing: final kilowatt hour test measurements .............................. 5

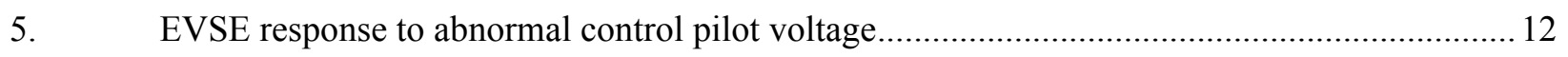

6. Energy efficiency testing: EVSE efficiency over a charge event....................................... 1314 


\section{Results from Operational Testing of the Siemens Smart Grid-Capable Electric Vehicle Supply Equipment}

\section{INTRODUCTION}

Idaho National Laboratory (INL) conducted testing and analysis of the Siemens smart grid-capable electric vehicle supply equipment (EVSE), which was a deliverable from Siemens for the U.S. Department of Energy FOA-554. INL has extensive knowledge and experience in testing advanced conductive and wireless charging systems though INL's support of the U.S. Department of Energy's Advanced Vehicle Testing Activity. This document details the findings from EVSE operational testing conducted at INL on the Siemens smart grid-capable EVSE (Figure 1). Testing conducted on the EVSE included energy efficiency testing, abnormal conditions testing, and charging of a production plug-in electric vehicle.
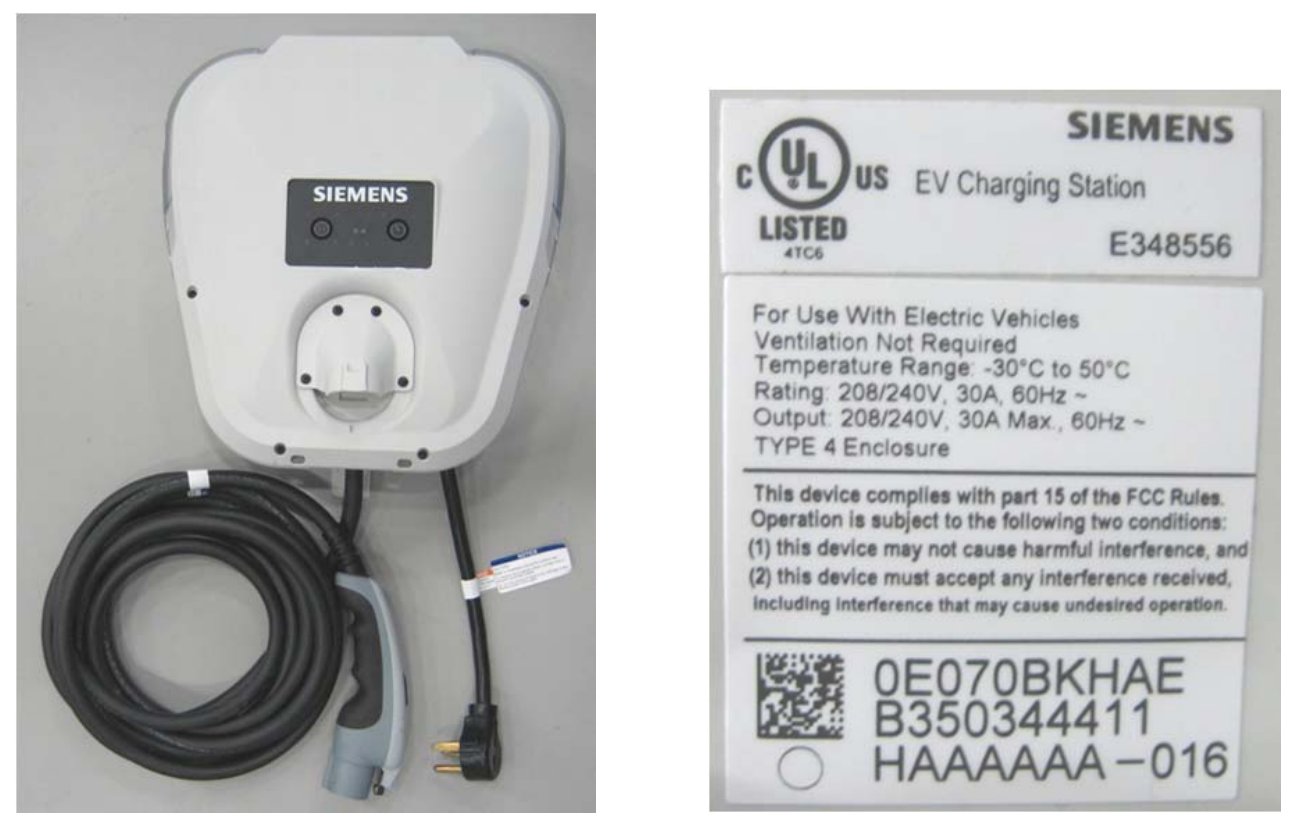

Figure 1. Siemens smart grid-capable EVSE.

\subsection{Laboratory Test Setup and Equipment}

For laboratory testing of the EVSE, vehicle emulation equipment was utilized, including a control pilot emulation module and a programmable alternating current load bank. The control pilot emulation module contained multiple resistors and a National Instruments' relay module that was controlled to provide proper resistance to the control pilot during testing in order to request the desired operation state. To draw power from the EVSE, a programmable alternating current load bank, which is capable of up to $9.0 \mathrm{~kW}$, was utilized (Figure 2).

Two pieces of calibrated measurement equipment (Figure 3) were used to measure voltage, current, and energy at multiple nodes during testing. A Hioki 3390 power meter was used to measure the input and output nodes and control the pilot signal of the EVSE. An Eaton IQ 250-watt hour meter, with a GE CTM-0C current transformer, also was used to measure the output node of the EVSE. 


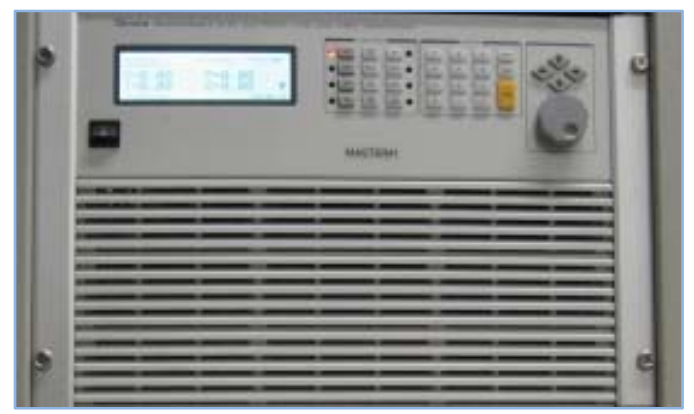

Figure 2. Programmable AC load bank (up to $9.0 \mathrm{~kW}$ ).
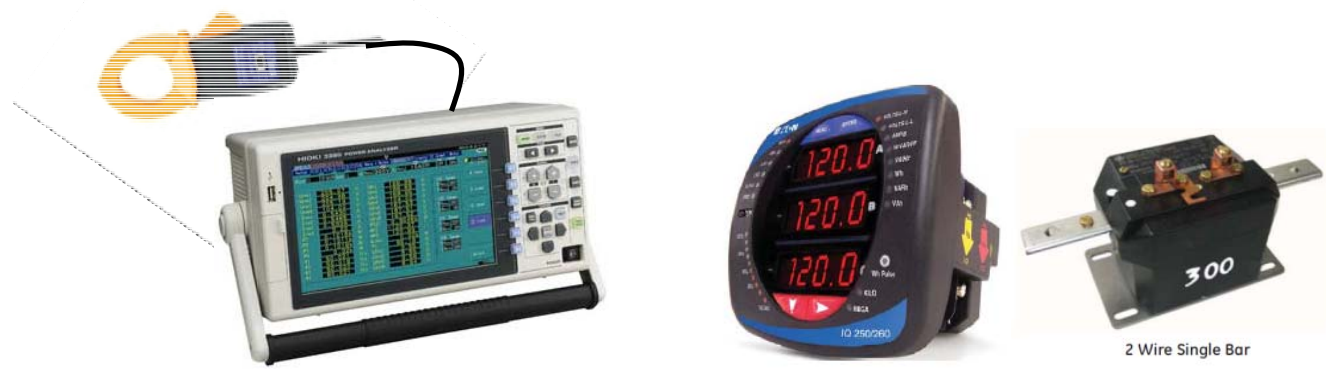

Figure 3. Hioki 3390 power meter and Eaton IQ 250 watt-hour meter with GE CTM-0C current transformer.

A schematic of the test setup is shown in Figure 4. The input voltage of 208 VAC was supplied from a single, 40-A circuit breaker to a safety stop (i.e., E-stop) module that contained two contactors (one per line) and a status light. The voltage output from the E-stop module was connected to the EVSE input connector. The EVSE output was connected to an enclosure that housed the Eaton IQ250 watt-hour meter. Next in the series, the control pilot emulation module was connected to provide the appropriate resistance for the desired J1772 state. Finally, power was absorbed by the alternating current programmable load. The Hioki voltage taps and current clamps were located as shown in Figure 4 and detailed in Table 1.

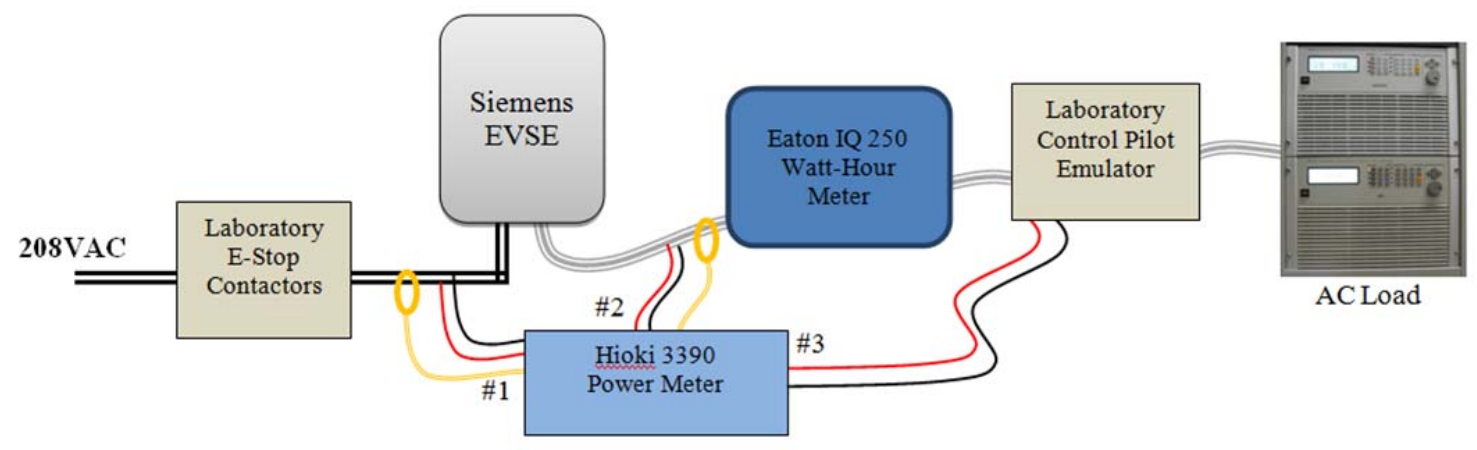

Figure 4. Schematic drawing of the laboratory test setup. 
Table 1. Hioki signal channel node locations.

\begin{tabular}{lll}
\hline Hioki Channel & \multicolumn{1}{c}{ Voltage Node } & \multicolumn{1}{c}{ Current Node } \\
\hline Channel 1 & Line voltage input to EVSE & Line current to EVSE \\
Channel 2 & Output from EVSE J1772 connector & Output from EVSE J1772 connector \\
Channel 3 & Control pilot signal & Open \\
\hline
\end{tabular}

A schematic of the 240-VAC test setup is shown in Figure 5. The input voltage of $240 \mathrm{VAC}$ was supplied from a single, 30 -A circuit breaker, and power was curtailed to $5.5 \mathrm{~kW}$ using the Siemens user application by limiting the current draw to $24 \mathrm{~A}$ (i.e., $80 \%$ of circuit breaker rating). The Eaton IQ250 watt-hour meter was not incorporated into the test setup. The voltage output from power supply was connected to the EVSE input connector. The EVSE output was connected to the breakout box to allow for measurement connections. Finally, power was absorbed by the 2015 Nissan Leaf. The Hioki voltage taps and current clamps were located as shown in Figure 5 and detailed in Table 1 (similar to the laboratory setup).

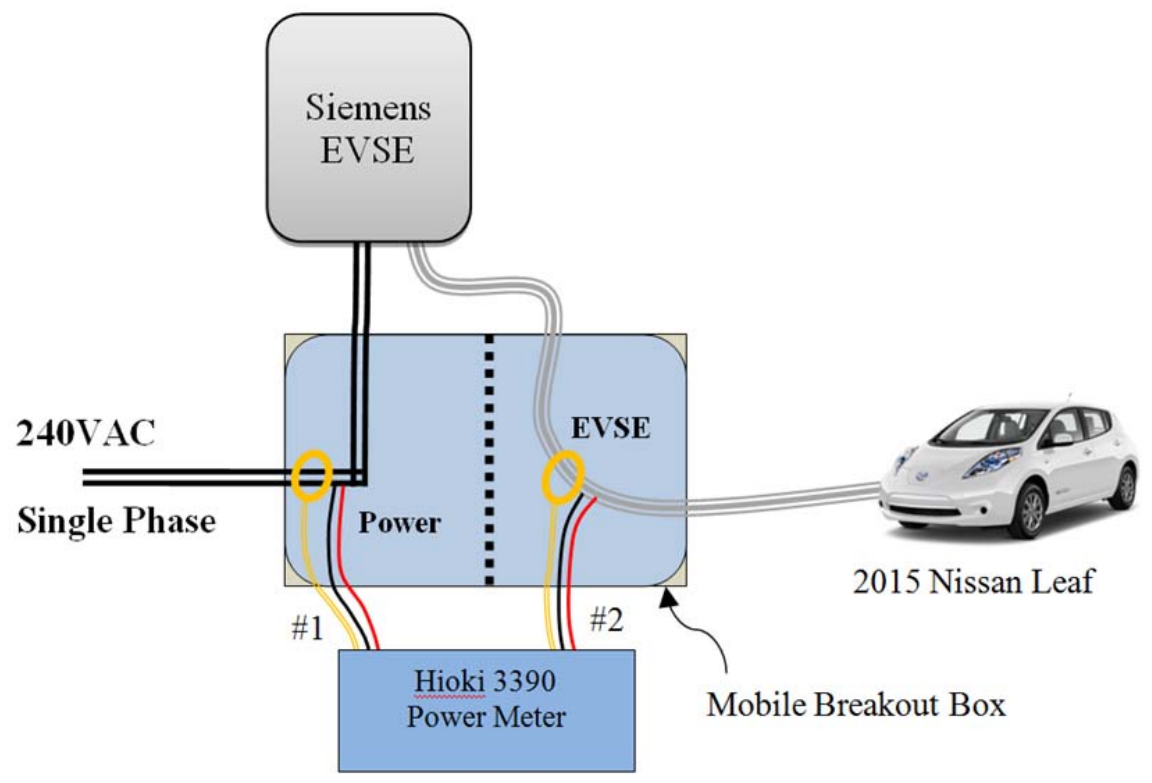

Figure 5. Schematic drawing of the 240-VAC single-phase test setup.

\section{ENERGY EFFICIENCY TESTING}

Testing was conducted using the laboratory test setup at seven EVSE output power levels (i.e., $0.05 \mathrm{~kW}, 1.1 \mathrm{~kW}, 2.2 \mathrm{~kW}, 3.3 \mathrm{~kW}, 4.4 \mathrm{~kW}, 5.5 \mathrm{~kW}$, and $6.2 \mathrm{~kW}$ ). EVSE standby power consumption also was tested to determine the amount of energy the EVSE consumes while in a passive, non-charging state. Various power levels were chosen because they represent typical charge rates for a wide range of plug-in vehicles. The highest output power tested was $6.2 \mathrm{~kW}$, because of the 30-Amp current limit as indicated by the control pilot duty cycle of $50 \%$. The nominal input voltage was 208 VAC. Each power level was tested for 10 minutes. Details from the energy efficiency testing are described in the following subsections. 


\subsection{Electric Vehicle Supply Equipment Standby Power Consumption}

EVSE standby power consumption was tested for the following J1772 states: State A, State B, State C, and State D. State A is when the EVSE is not connected to the vehicle. In State B, the EVSE is connected to a vehicle, but the vehicle is not ready to charge; therefore, the contactor in the EVSE is open. In State C and State D, the EVSE is connected to a vehicle and the vehicle communicates to the EVSE that it is ready to charge; therefore, the contactor in the EVSE closes if all conditions are correct.

Results from testing of standby power consumption are summarized in Table 2 . The standby power of State $\mathrm{C}$ is about 3.0 watts greater than the standby power of State B when the LED is "On" and about 4.0 watts when the LED is "Off." This difference in power consumption between State C and B is likely due to the power required to keep the contactors closed in State $C$ and the change from 3.0 to 4.0 watts is from the LED being powered "On" or "Off." A slight increase in power consumption of 0.20 watts is seen when the WiFi module is "On" or "Off" and possibly actively searching for network connections.

Table 2. Siemens EVSE standby power in watts.

\begin{tabular}{lcccc}
\hline J1772 State & $\begin{array}{c}\text { LED “On" } \\
\text { WiFi "On" }\end{array}$ & $\begin{array}{c}\text { LED “On" } \\
\text { WiFi "Off" }\end{array}$ & $\begin{array}{c}\text { LED “Off” } \\
\text { WiFi "On" }\end{array}$ & $\begin{array}{c}\text { LED “Off" } \\
\text { WiFi "Off" }\end{array}$ \\
\hline State A & 3.49 & 3.17 & 3.57 & 3.77 \\
State B & 5.44 & 5.81 & 3.67 & 3.83 \\
State C & 8.28 & 8.63 & 7.78 & 8.05 \\
State D & 5.17 & 5.31 & 5.15 & 4.79 \\
\hline
\end{tabular}

LED $=$ light-emitting diode

\subsection{Electric Vehicle Supply Equipment Efficiency}

EVSE efficiency, as measured by the Hioki 3390 power meter, can be found in Table 3. Each power level was tested for 10 minutes. The efficiency was calculated from the measured energy output from the EVSE divided by the measured energy input to the EVSE over the 10-minute test. Of the seven power levels measured, efficiency is greater than or equal to $90 \%$ when power is drawn from the EVSE at 1.1 to $5.5 \mathrm{~kW}$. The efficiency at very low power levels (i.e., 50 watts) is lower because the EVSE's standby power is large compared to the output power drawn from the EVSE.

Table 3. Siemens EVSE efficiency testing LED "OFF" WiFi "OFF."

Average EVSE Efficiency

Test Condition

(Output Power/Input Power)

$\begin{array}{ll}50 \text { watts } & 84.3 \% \\ 1.1 \mathrm{~kW} & 99.3 \% \\ 2.2 \mathrm{~kW} & 99.4 \% \\ 3.3 \mathrm{~kW} & 99.3 \% \\ 4.4 \mathrm{~kW} & 99.1 \% \\ 5.5 \mathrm{~kW} & 99.0 \% \\ 6.2 \mathrm{~kW} & 98.9 \%\end{array}$

\subsection{Electric Vehicle Supply Equipment Energy Measurement}

Energy measurement tests were conducted using both the laboratory test setup (at 208 VAC) and the 240 VAC test setup, as shown in Figures 4 and 5 and the Siemens EVSE user application. The EVSE user application was required to obtain a $\mathrm{kWh}$ display that allows for viewing of event charge energy (Home 
$\mathrm{Tab}$ ) and cumulative usage (Usage Tab) due to this being a residential EVSE. INL testing activities leveraged this user application interface to assess the energy measurements of the EVSE for these tests. The final kilowatt-hour measurements from each test are summarized in Table 4.

Table 4. Siemens energy efficiency testing: final kilowatt hour test measurements.

\begin{tabular}{lcccc}
\hline Test Condition & $\begin{array}{c}\text { Hioki Power } \\
\text { Meter }\end{array}$ & $\begin{array}{c}\text { IQ 250 Watt Hour } \\
\text { Meter }\end{array}$ & $\begin{array}{c}\text { Siemens EVSE kWh } \\
\text { Display (Home Tab) }\end{array}$ & $\begin{array}{c}\text { Siemens EVSE kWh } \\
\text { Display (Usage Tab) }\end{array}$ \\
\hline $208 \mathrm{~V}, 6.2 \mathrm{~kW}$ & $20.01 \mathrm{kWh}$ & $20.04 \mathrm{kWh}$ & $0.00 \mathrm{kWh}$ & $0.00 \mathrm{kWh}$ \\
$240 \mathrm{~V}, 5.5 \mathrm{~kW}$ & $1.36 \mathrm{kWh}$ & NA & $0.00 \mathrm{kWh}$ & $0.00 \mathrm{kWh}$ \\
$208 \mathrm{~V}, 6.2 \mathrm{~kW}$ & $4.15 \mathrm{kWh}$ & $4.15 \mathrm{kWh}$ & $0.00 \mathrm{kWh}$ & $0.39 \mathrm{kWh}$ \\
$240 \mathrm{~V}, 5.5 \mathrm{~kW}$ & $2.01 \mathrm{kWh}$ & NA & $0.00 \mathrm{kWh}$ & $0.21 \mathrm{kWh}$ \\
$208 \mathrm{~V}, 6.2 \mathrm{~kW}$ & $3.00 \mathrm{kWh}$ & $3.00 \mathrm{kWh}$ & $0.00 \mathrm{kWh}$ & $0.60 \mathrm{kWh}$ \\
\hline
\end{tabular}

In the initial energy measurement test using laboratory-supplied 208-VAC, neither the Home Tab (figure 6) $\mathrm{kWh}$ display nor the Usage Tab (figure 7) $\mathrm{kWh}$ display incremented during the 6.2-kW charge event. Figures 6 and Figure 7 show screen shots of the web application at the end of the $6.2 \mathrm{~kW}, 208$ VAC test. Observations from the web application also include the following:

1. The "Home Tab" (figure 6) displays a value for power that corresponds to laboratory power measurements of the EVSE output power as indicated on the cloud App "Home Tab" (i.e., cloud app Home $\mathrm{Tab}=6.1473 \mathrm{~kW}$, INL Hioki power meter $=6.15 \mathrm{~kW}$ ). Additionally the voltage displayed on the "Home Tab" indicated $238 \mathrm{~V}$. It appears that the EVSE voltage measurement is not measuring voltage from line to line but is instead adding the measured voltage of each line with respect to ground.

2. The plot function provided on the Usage Tab (figure 7) indicated that energy was being accumulated (e.g., bar graph was building), but it was too difficult to determine an appropriate value because the Y axis did not provide a value or units on axis

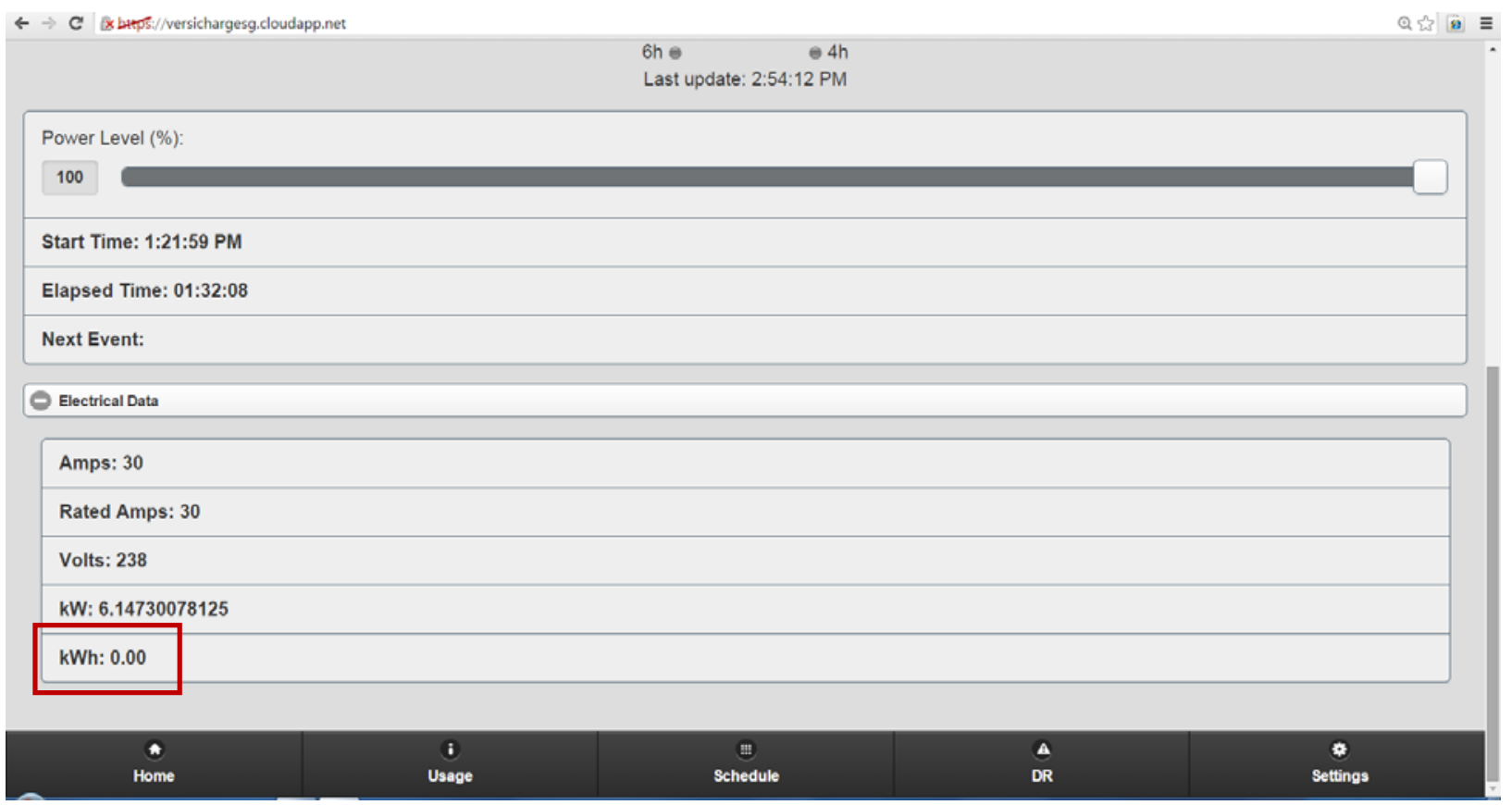

Figure 6. Home Tab at the end of the test. 


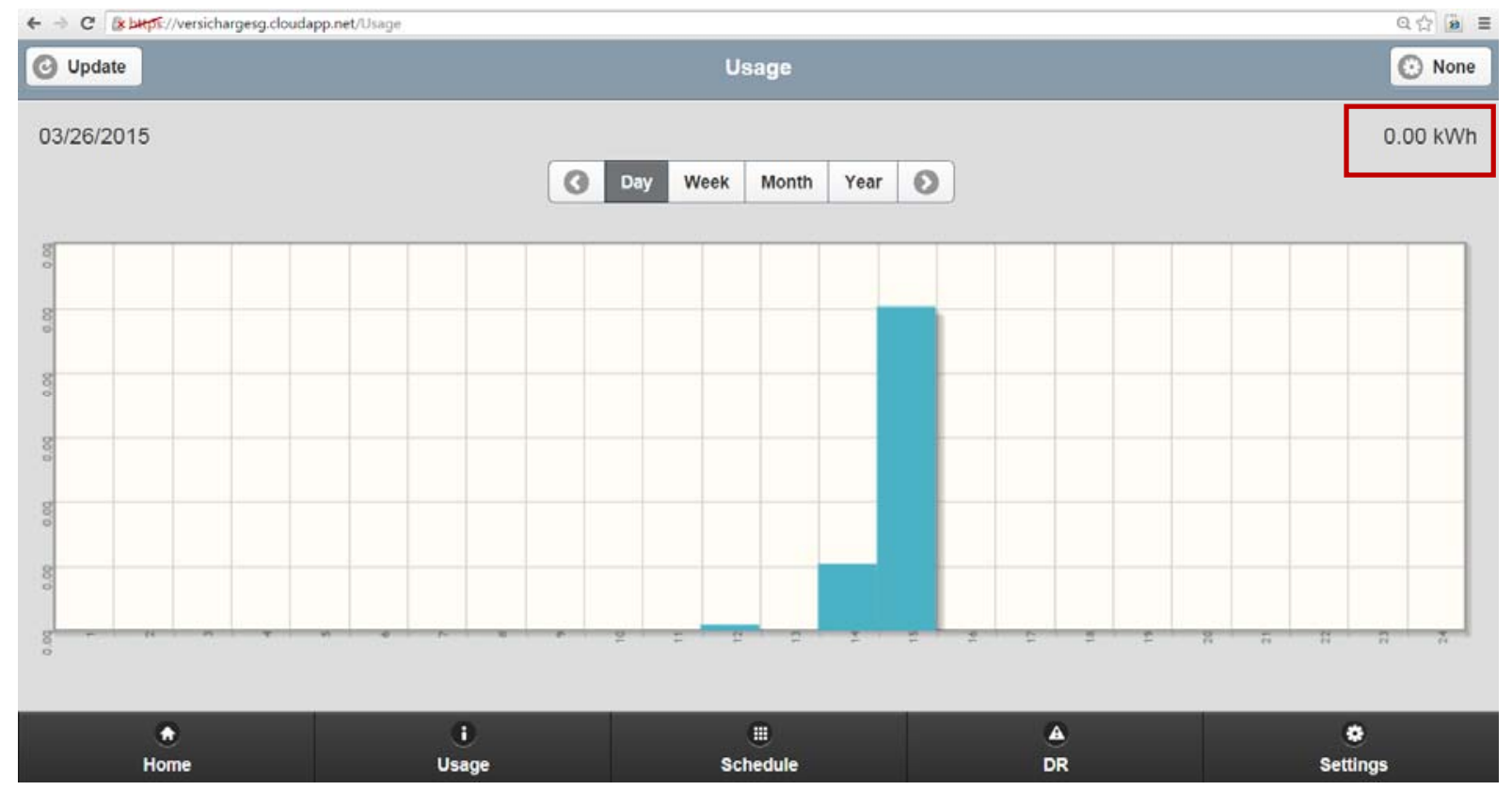

Figure 7. Usage Tab at the end of the test.

Because of the initial test results and the inability to determine kWh energy measurements as measured by the EVSE, follow up discussions were held with the Siemens engineering staff. Software updates were made to the cloud app software by the Siemens engineers in an attempt to resolve these issues. Also, Siemens requested that INL test the EVSE at the residential voltage level of $240 \mathrm{VAC}$ single-phase instead of 208 VAC single-phase, even though the EVSE is UL listed for both 208 VAC and 240 VAC (Figure 1).

Subsequent testing on the recommended single-phase, $240 \mathrm{VAC}$ was performed for approximately 20 minutes using a 2015 Nissan Leaf. The EVSE was tested at a reduced power level of $80 \%(5.54 \mathrm{~kW})$, current $=23 \mathrm{Amps}$, and resulted in $1.36 \mathrm{kWh}$ of energy through the EVSE as recorded by the INL data acquisition system. The end-of-test Home Tab information (shown in Figure 8) shows that current $=$ $23 \mathrm{Amps}$, volts $=237 \mathrm{VAC}$, and power $=5.54 \mathrm{~kW}$, but the $\mathrm{kWh}$ display remained 0.00 . The Usage Tab (shown in Figure 9) provided a plot that was still too difficult to determine the Y axis value and units; the accumulated energy value in the upper right corner remained $0.00 \mathrm{kWh}$. Table 4 provides a summary of these results. 


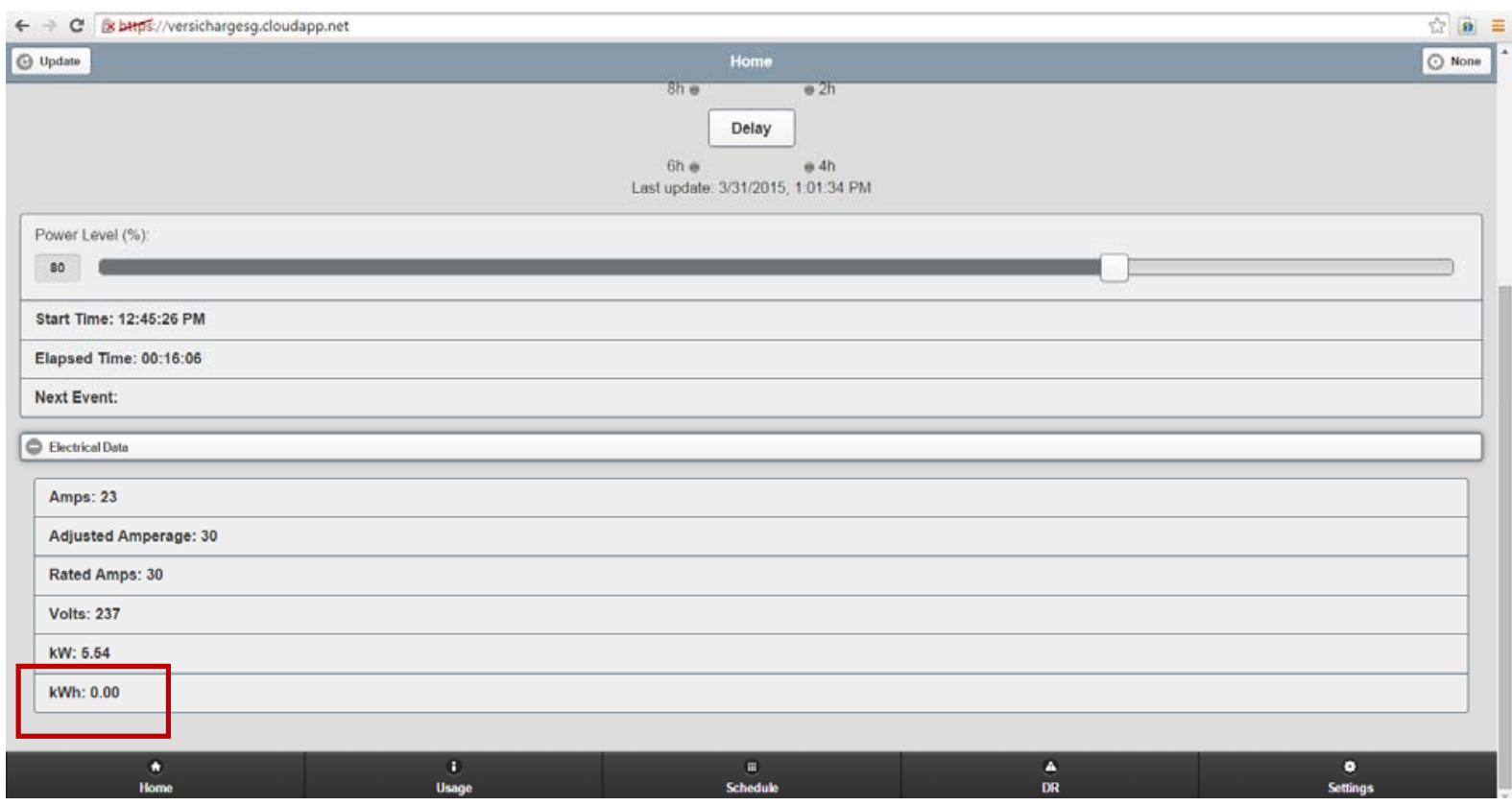

Figure 8 . Home Tab $1.36-\mathrm{kWh}, 240-\mathrm{V}$ test shows $80 \%$ power, $23 \mathrm{Amps}$, and duration of test.

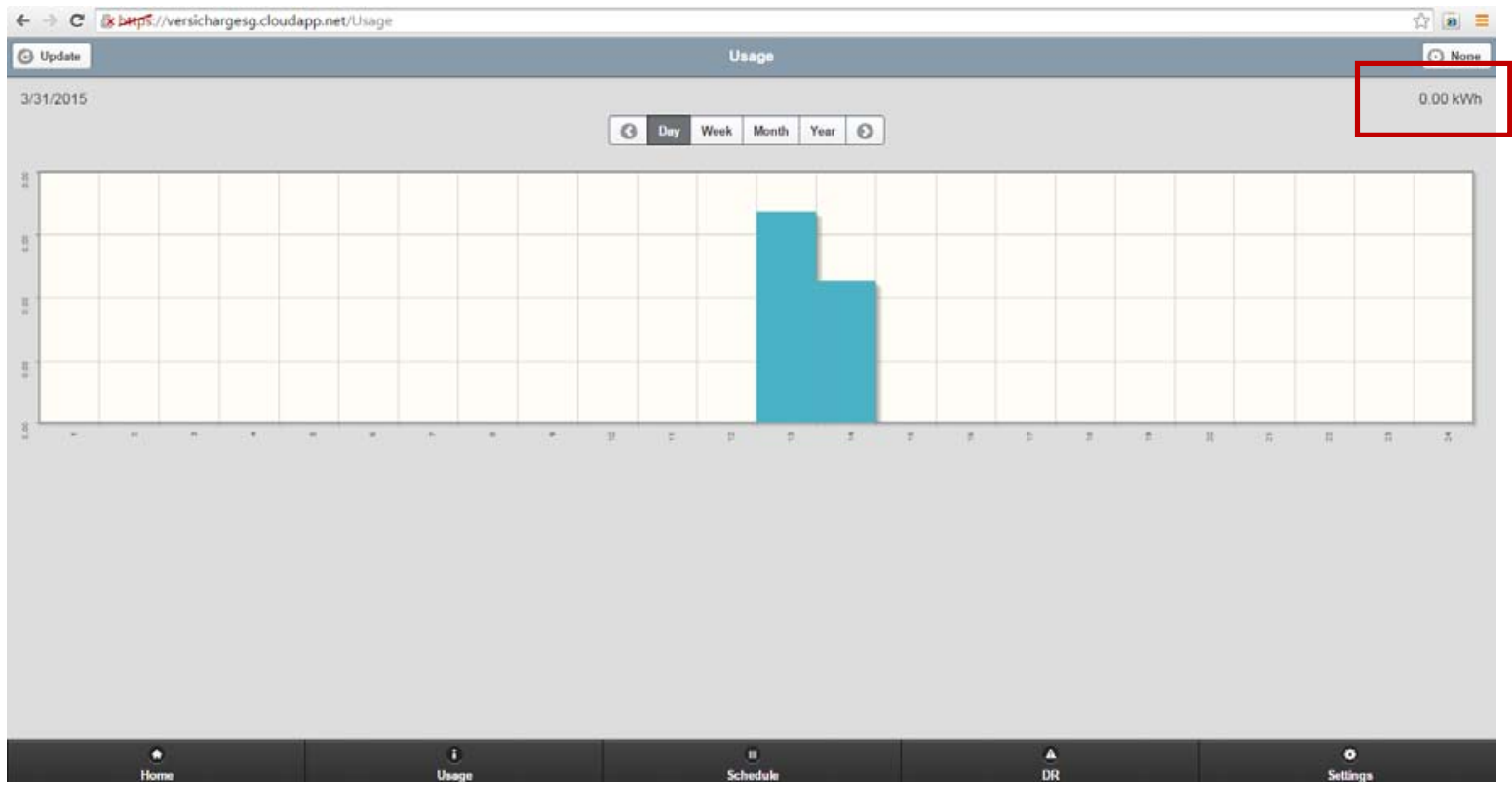

Figure 9. Usage Tab plot tab at end of test, 80\% power, 23 Amps, and $0.00 \mathrm{kWh}$.

Further testing of the EVSE at 208 VAC was performed in the laboratory to attempt to understand the difference that existed between $240 \mathrm{VAC}$ and $208 \mathrm{VAC}$. The test spanned 45 minutes and resulted in 4.15 $\mathrm{kWh}$ of energy through the EVSE at a power of $6.1 \mathrm{~kW}$ and a current of 30 Amps. Observations of the cloud App "Home Tab" indicated a power and current that were consistent with INL data acquisition; however, the cloud App "Home Tab" kWh meter was still 0.00 and the voltage value was $237 \mathrm{~V}$. It was observed that the cloud App "Usage Tab" $\mathrm{kWh}$ display did increment up to $0.39 \mathrm{kWh}$ (Figure 10). This does not match the $4.15 \mathrm{kWh}$ measured by INL's data acquisition. 


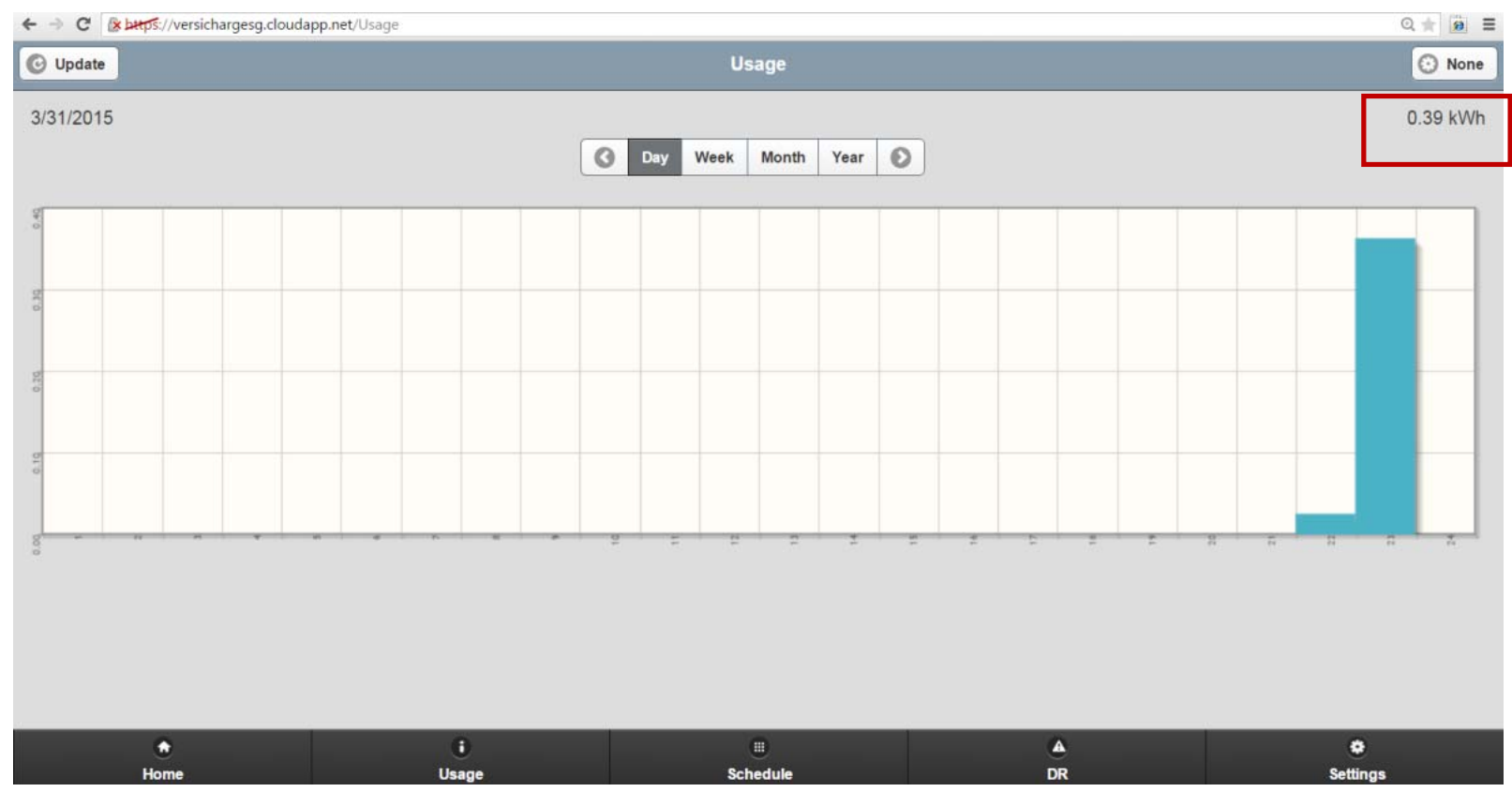

Figure 10. Screen shot of the Usage Tab after the conclusion of tests, showing $0.39 \mathrm{kWh}$ of energy.

The previous results were communicated to the engineering team of Siemens and it was determined that the EVSE needed a new WiFi module, with updated firmware, to correct the inaccuracies observed in the earlier watt-hour measurement tests. After receiving the module the next day, it was installed and additional energy tests were performed to validate the EVSE energy measurements. INL energy measurement tests were performed at both $240 \mathrm{VAC}$ and $208 \mathrm{VAC}$. The test at $240 \mathrm{VAC}$ spanned 20 minutes and accumulated $2.0 \mathrm{kWh}$ of energy at a power level of $5.52 \mathrm{~kW}$ ( $80 \%$ of the maximum), current $=23$ Amps, and voltage $=237$ V. At the end of the test, the "Home Tab" (figure 11) showed 0.00 for the $\mathrm{kWh}$ value, but after 23 minutes, the "Usage Tab" $\mathrm{kWh}$ incremented up to a value of $0.20 \mathrm{kWh}$ (shown in Figure12). The energy reading was pulled at 2:42 23; this was 23 minutes after test completion. The Usage Tab continued to provide an incrementing value for 23 minutes after the power was disconnected. The reason for the time delay is unknown. 


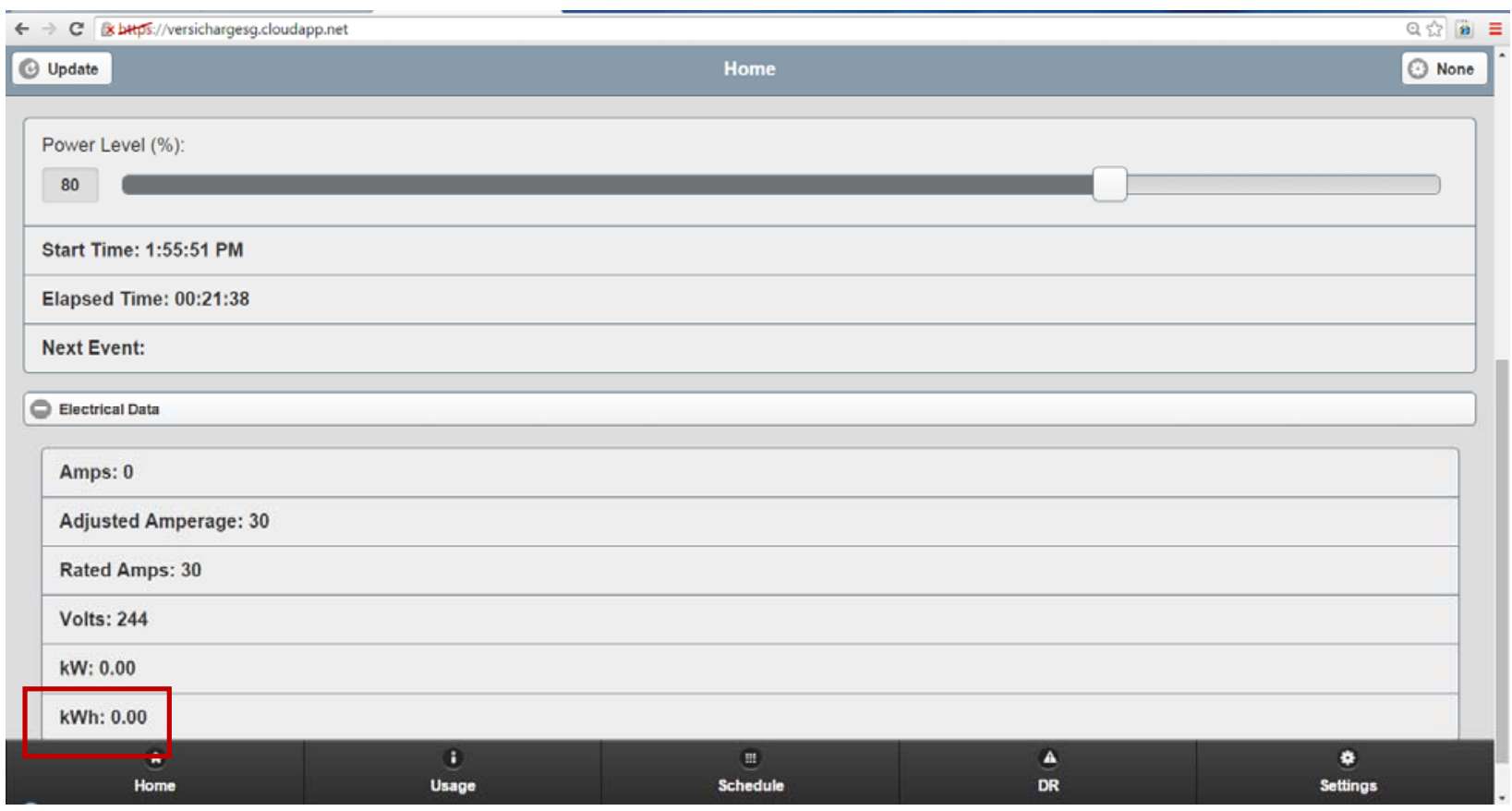

Figure 11. Home Tab at the end of the $2.0 \mathrm{kWh}$ test, showing 21 minutes elapsed time of test; the $\mathrm{kWh}$ of energy is 0.00 .

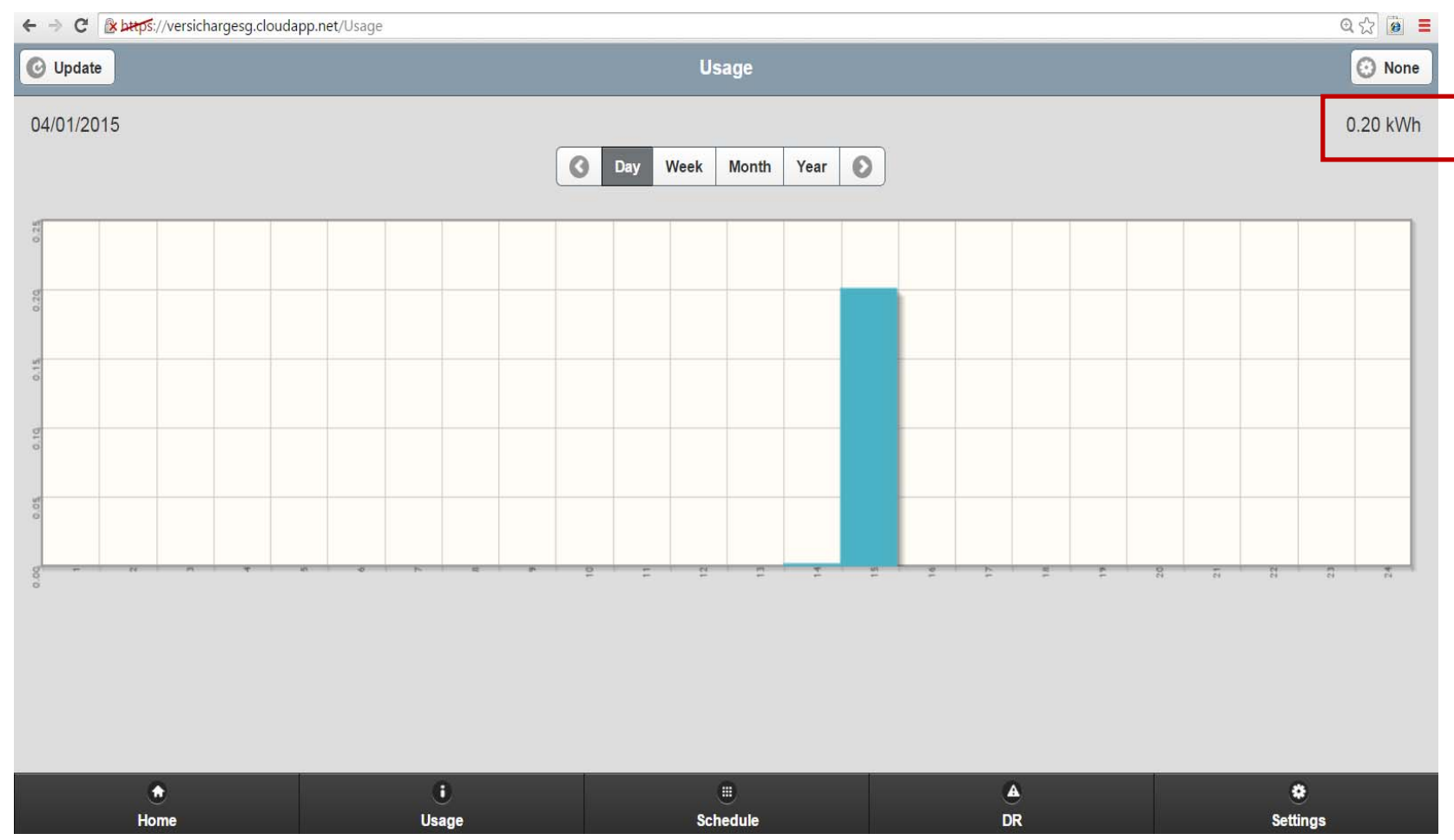

Figure 12. Usage Tab End-of-test kWh reading shows that a $0.20-\mathrm{kWh}$

An additional test was conducted in the laboratory at $208 \mathrm{VAC}, 6.1 \mathrm{~kW}$, and $30 \mathrm{Amps}$ to further investigate. This 208-VAC test spanned a total of 1.5 hours $(30$ min current draw followed by 60 min with no current draw). The test resulted in $3.0 \mathrm{kWh}$ of energy being transferred through the EVSE as measured by the INL data acquisition system. The "Home Tab" showed $0.00 \mathrm{kWh}$ for the duration of the 
test, but the "Usage Tab" indicated $0.20 \mathrm{kWh}$ at the beginning of the test and incremented up to $0.80 \mathrm{kWh}$ of energy by the end of the test. The "update" button in the app was pushed approximately every 10 seconds throughout the test. The "Usage Tab" kWh was manually recorded into the INL data acquisition system to be approximately time aligned (to within 10 seconds) with the INL power and energy measurements. The difference from the final to initial $\mathrm{kWh}$ reading on the Usage Tab was $0.60(0.80$ 0.20) (Figures 12 and 13). This is significantly different than the $3.0 \mathrm{kWh}$ measured by the INL data acquisition system. Figure 16 shows the INL laboratory measurements for this test compared to the "Usage Tab" kWh reading. These results were shared with the engineers at Siemens for use in troubleshooting the EVSE.

Initial hypotheses for the causes of the $\mathrm{kWh}$ issues included 10x scaling of the displayed value, and/or time latency from measurement to the display of the value on the Usage Tab. But these hypotheses do not appear to be the cause. If units scaling and/or time latency were the cause, it would be expected that the "Usage Tab" $\mathrm{kWh}$ would have stopped incrementing at $0.50 \mathrm{kWh}$ at a test time of approximately 2,800 seconds (Figure 14). Instead the Usage Tab kWh continued to increment for an additional 45 minutes after current draw ceased.

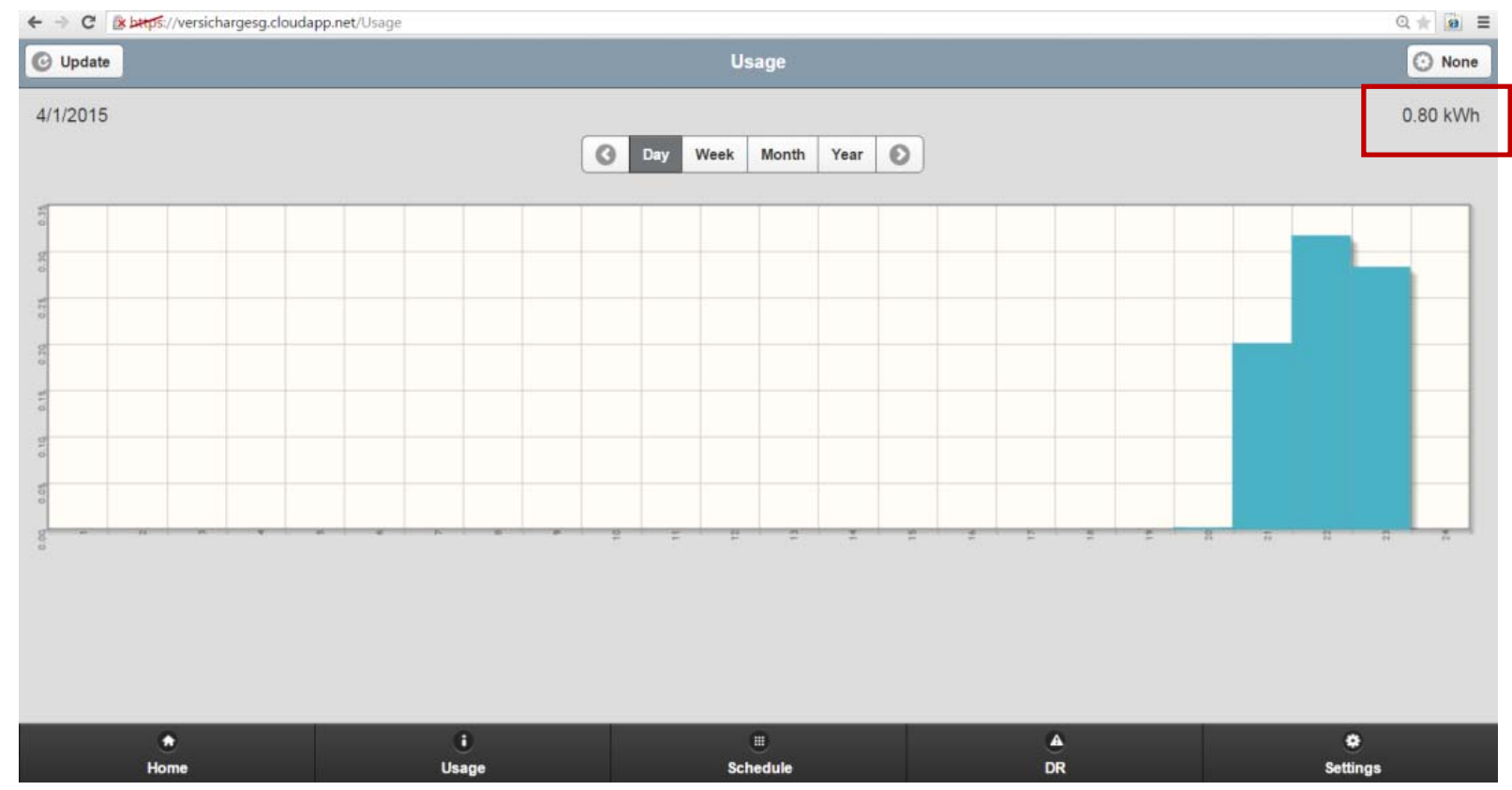

Figure 13. Screen shot of the Usage Tab after conclusion of 208-VAC testing and 240-VAC testing. This has $0.21 \mathrm{kWh}$ of the $240-\mathrm{VAC}$ test and $0.59 \mathrm{kWh}$ for $208 \mathrm{VAC}$. 


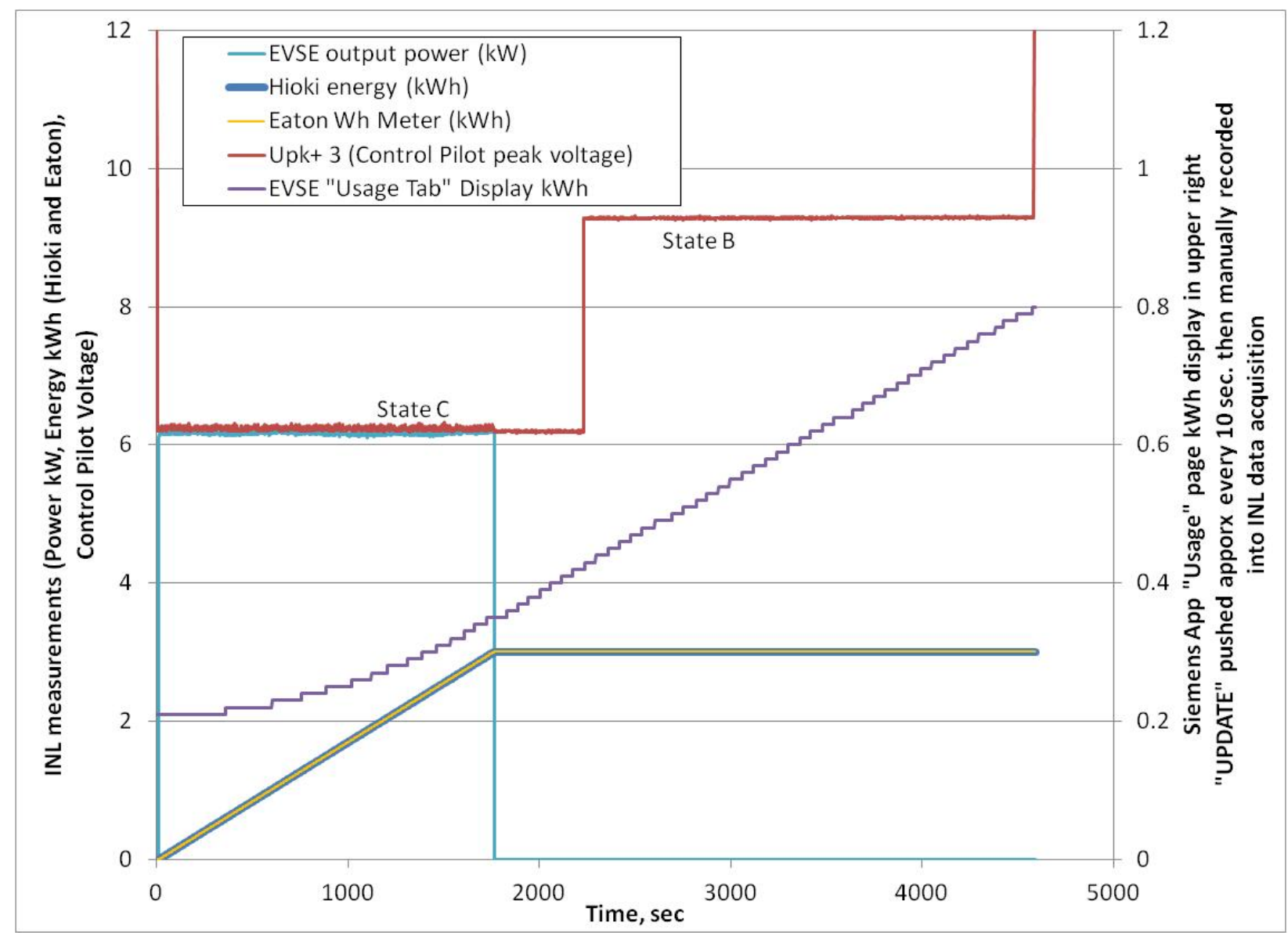

Figure 14. Energy measurement of 208-VAC test, showing the energy measurements for INL instrumentation and the EVSE Usage Tab.

\section{ABNORMAL CONDITIONS TESTING}

In addition to the previously described testing at normal conditions, testing was also conducted to determine the response of EVSE to abnormal input conditions.

\subsection{Electric Vehicle Supply Equipment Response to Abnormal Control Pilot Voltage}

Previously, each of the control pilot states was tested (i.e., State A, B, C, and D). Additionally, tests were conducted at control pilot voltages that are outside of the voltages specified by Society of Automotive Engineers (SAE) J1772 for each control pilot state. Figure 15 shows the SAE J1772 recommended practices for the EVSE manufacturer for state determination from the control pilot voltage.

Two control pilot voltage conditions were tested: (1) control pilot $=7.3 \mathrm{~V}$ (between State B and C) and (2) control pilot $=4.8 \mathrm{~V}$ (between State $\mathrm{C}$ and $\mathrm{D}$ ). The various tests arrived at the in-between states from each of the previously defined system states (i.e., A, B, C, and D) by sequence stepping (e.g., from $\mathrm{A}$ to $\mathrm{B}$ and $\mathrm{C}$ and from $\mathrm{A}$ to $\mathrm{B}$ to $\mathrm{B}$ and $\mathrm{C}$, etc.). The results shown in Table 5 summarize the EVSE response to these in-between voltage conditions. Test 3 shows that the contactor closed at the nominal condition (i.e., $6.0 \mathrm{~V}$ ) and stayed closed as the test progressed to the in-between B and C state. 


\begin{tabular}{lccc}
\hline & Minimum & Nominal & Maximum \\
\hline Positive Voltage, State A & 11.40 & 12.00 & 12.60 \\
Positive Voltage, State B & 8.36 & 9.00 & 9.56 \\
Positive Voltage, State C & 5.48 & 6.00 & 6.49 \\
Positive Voltage, State D & 2.62 & 3.00 & 3.25 \\
Negative Voltage - States B, C, D, and F & -11.40 & -12.00 & -12.60 \\
\hline
\end{tabular}

Figure 15. SAE J1772 (Version 2010)-recommended practice of control pilot voltage range for each state.

Table 5. EVSE response to abnormal control pilot voltage.

\begin{tabular}{lccc}
\hline \multicolumn{1}{c}{ Initial Condition } & CP Voltage Peak+ & Test Condition & Siemens EVSE Response \\
\hline 1. State A & $7.3 \mathrm{~V}$ & Between B and C & Contactor did not close \\
2. State B & $7.3 \mathrm{~V}$ & Between B and C & Contactor did not close \\
3. State C & $7.3 \mathrm{~V}$ & Between B and C & Contactor closed \\
4. State D & $7.3 \mathrm{~V}$ & Between B and C & Contactor did not close \\
5. State A & $4.9 \mathrm{~V}$ & Between C and D & Contactor did not close \\
6. State B & $4.9 \mathrm{~V}$ & Between C and D & Contactor closed \\
7. State C & $4.9 \mathrm{~V}$ & Between C and D & Contactor closed \\
8. State D & $4.9 \mathrm{~V}$ & Between C and D & Contactor did not close \\
\hline
\end{tabular}

\section{VEHICLE CHARGING TESTS (CHEVY VOLT)}

Vehicle charging tests were performed with a 2012 Chevrolet Volt (Figure 16), which is an extended-range electric vehicle, to observe EVSE operations during real-world charging events. Under these conditions, the efficiency and standby loads of the EVSE were observed and measured. Secondary observations were made, which included charge ramp up and ramp down as dictated by the vehicle's onboard charger.

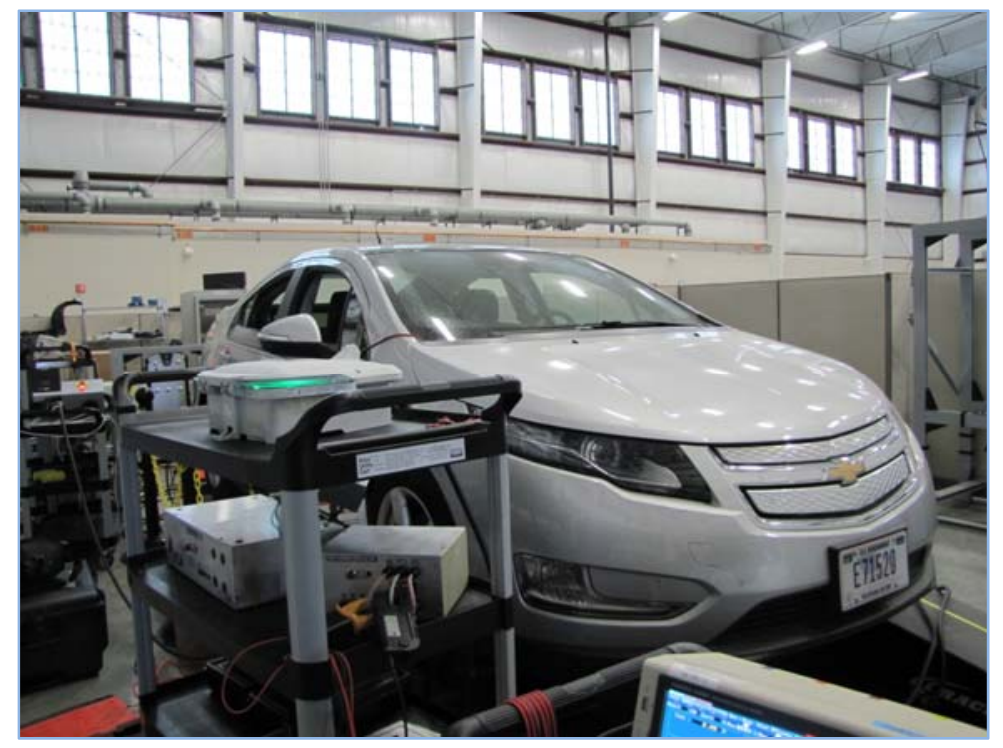

Figure 16. EVSE tests using a 2012 Chevrolet Volt. 
The Volt battery pack was depleted prior to testing until charge-sustaining mode was reached. A full charge event was then initiated, monitored, and recorded using the Hioki 3390 power analyzer and Eaton IQ 250 watt-hour meter.

Figure 17 shows the connection schematic for the Siemens charging equipment, Hioki 3390 power meter, and the Eaton IQ 250 watt-hour meter used during the vehicle tests. Measurement at the input of the EVSE is Node \#1 and measurement at the SAE J1772 output connector of the EVSE is Node \#2.

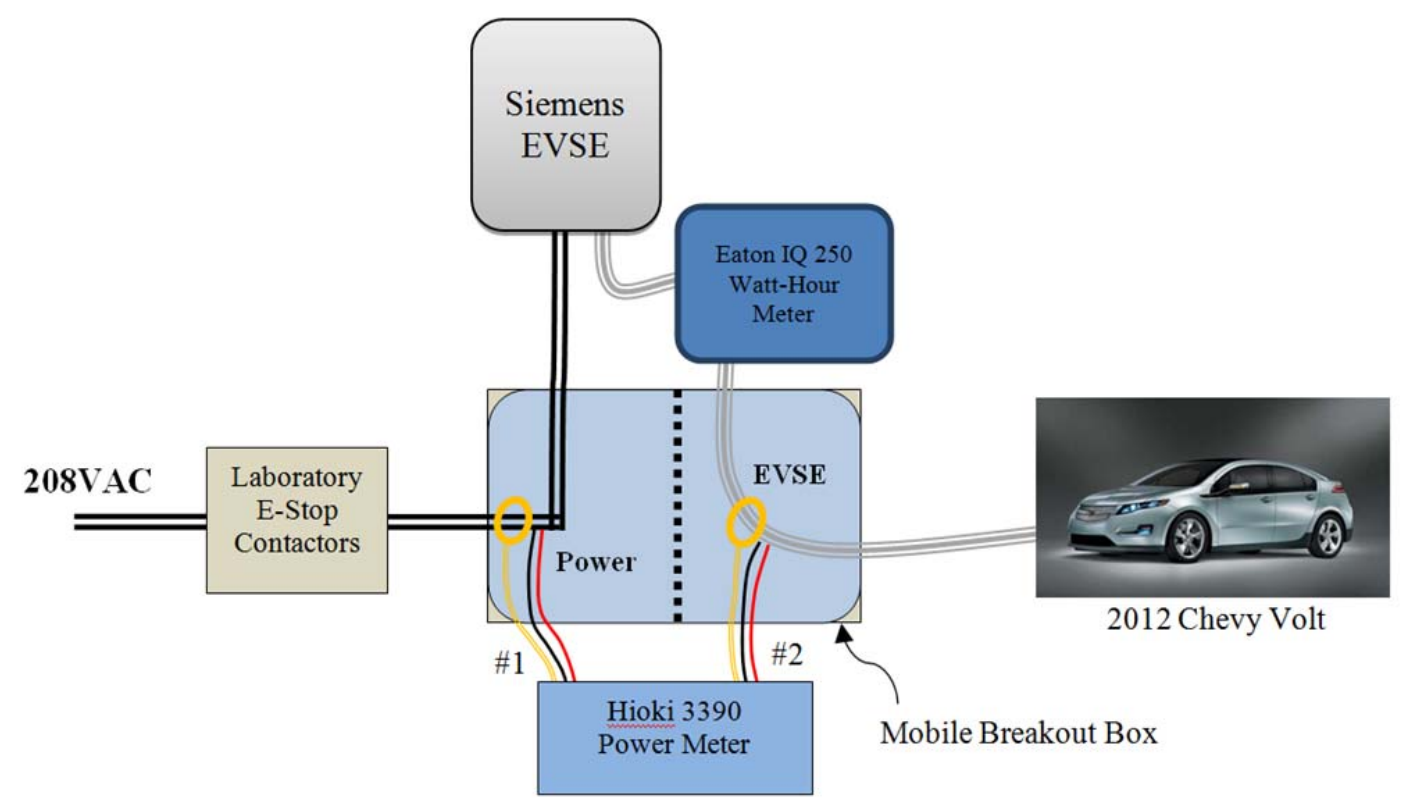

Figure 17. Schematic drawing of the vehicle test setup.

\subsection{Electric Vehicle Supply Equipment Energy Efficiency}

The EVSE energy transfer was measured throughout a full charge 208 VAC event for the Chevy Volt. This charge event was approximately 4.5 hours in duration and nominal power transfer was $3.1 \mathrm{~kW}$, as controlled by the vehicle's battery management system. From the cumulative measured energy delivered to the vehicle and the cumulative energy supplied to the EVSE from the grid, the efficiency of the EVSE was determined over the entire charge event. Table 6 shows the energy efficiency of the EVSE which is defined as the total energy output from the EVSE divided by the total energy input to the EVSE over the entire duration of the charge event. The EVSE efficiency was measured to be $99.2 \%$. This correlates well to the $99.3 \%$ result shown in Table 4 that was measured during laboratory testing at the slightly higher 3.3-kW power level.

Table 6. Energy efficiency testing: EVSE efficiency over a charge event.

Test Condition

Vehicle Full Charge Event
EVSE Efficiency

(Total Output Energy/Total Input Energy)

\subsection{Electric Vehicle Supply Equipment Response to Interrupted Grid Power}


Testing was conducted on the EVSE to identify the EVSE response to a grid power outage. This test was conducted using the Chevy Volt vehicle testing protocols described in Section 4.1. A vehicle charge event was initiated and steady state charge power was reached and monitored for approximately 1 minute to ensure steady state operation. Grid power (i.e., 208 VAC) was then interrupted for the EVSE power input. As expected, the EVSE ceased to function or provide voltage to the vehicle. Grid power was restored after approximately 5 seconds and the EVSE rebooted. After approximately 60 seconds, the EVSE reinitializes with the delay mode activated. After approximately 10 minutes, the delay mode expired and the charge event resumed without the need for outside intervention as shown in figure 18 .

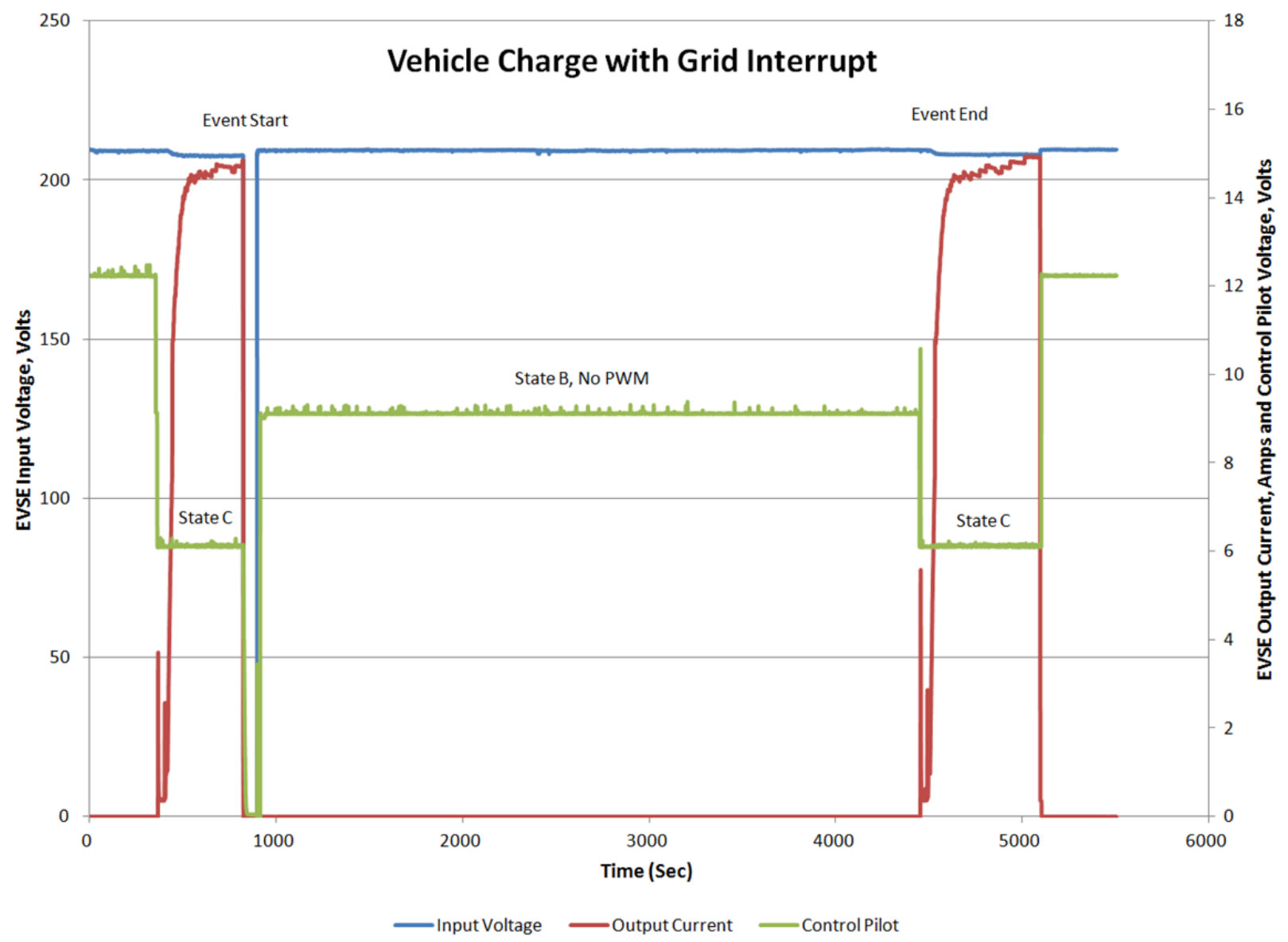

Figure 18. EVSE resumes charging after approx. 10 minutes in response to 208 VAC grid interrupt

\subsection{Electric Vehicle Supply Equipment Response to Curtailment of Grid Power}

Testing was conducted on the EVSE to identify the EVSE response to a grid power curtailment request combined with an interrupted grid power event. This test was conducted using the Chevy Volt vehicle testing protocols described in Section 4.1. A vehicle charging event was initiated after a curtail request was issued for a reduction of $80 \%$ of full power via the user application. The EVSE, in turn, reduced the control pilot pulse width modulation (PWM) duty cycle down to $20 \%$ (i.e., $80 \%$ reduction). As expected, the vehicle ramped down its current draw to just above 6 Amps when plugged in. A grid interrupt event (i.e., disconnect 208 VAC from EVSE input) was performed within the curtailment timeframe to determine if the curtailment request was retained. Because the EVSE's input power was 
removed during the test, the EVSE did not retain the commanded power curtailment. After input power was reconnected and EVSE initialization, the EVSE resumed the PWM duty cycle correlating to the EVSE maximum current rating (i.e., 50\% duty cycle). The vehicle then also responded as expected by increasing charge current draw to 15 Amps. Interruption of grid input power to the EVSE during a curtailment event resulted in the charging system (i.e., EVSE and vehicle) no longer retaining the reduced power level curtailment request.

In another test, power was curtailed by issuing a demand response reduction of $100 \%$ of full power via user application. The EVSE, in turn, reduced the control pilot PWM duty cycle to $20 \%$, but no further. The vehicle responded and current was drawn at near 6 Amps. At the end of the request, the power level was returned to maximum power level by returning to the $50 \%$ duty cycle in progression. The EVSE responded by resuming the appropriate control pilot PWM duty cycle percent for each step of percent power and ending at the $50 \%$ duty cycle (i.e., $100 \%$ power). The vehicle responded as expected by increasing to a maximum charge current draw of 15 Amps.

In the last test, power was curtailed by issuing a "Pause," using the pause button on the EVSE. The EVSE, in turn, opened the contactors and the control pilot changed to State B for the duration the button was enabled. After the pause button was disabled, the EVSE resumed the control pilot $50 \%$ duty cycle, the contactors closed, and the vehicle responded as expected by increasing charge current draw to 15 Amps. This sequence of events is shown in Figure 19.

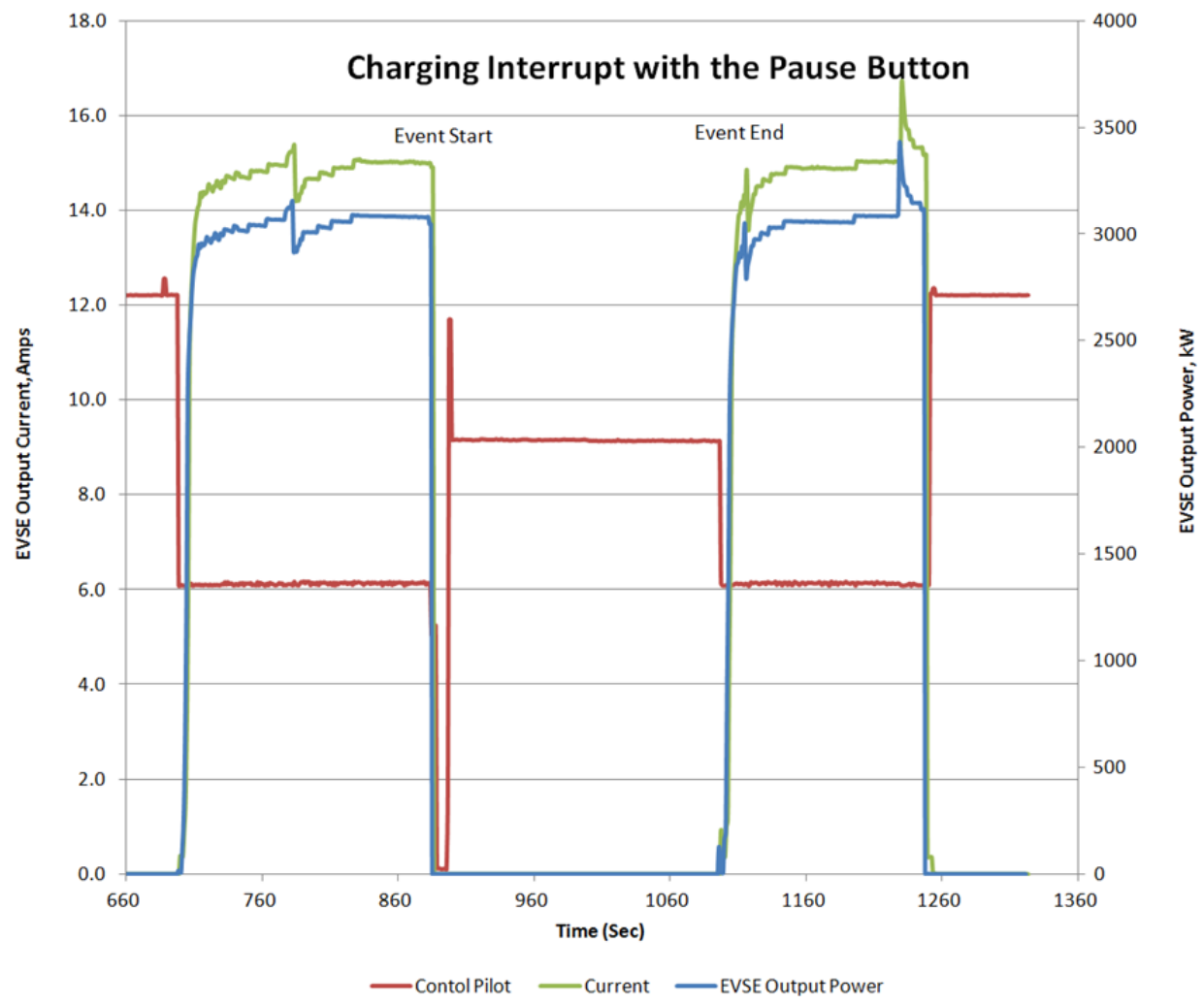

Figure 19. EVSE response to the pause button.

\section{SUMMARY}

INL tested the Siemens smart grid-capable EVSE in support of U.S. Department of Energy FOA-554. The energy efficiency, stand-by power consumption, and functionality per SAE J1772 were tested. The EVSE also was used to charge a 2012 Chevy Volt and 2015 Nissan Leaf to verify full functionality with a production plug-in electric vehicle. 
The test results of the Siemens EVSE showed the nominal operating efficiency is greater than $99.2 \%$ during Level 2 charging at $3.3 \mathrm{~kW}$. The standby power consumption was measured to be 3.5 watts in State A (i.e., vehicle not connected), 5.4 watts in State B (i.e., vehicle connected, but not ready to charge), and 8.3 watts in State C and 5.2 watts in State D (i.e., vehicle connected and ready to charge). The EVSE LED status indicators provide the user with the status via LEDs that illuminate green (e.g., power and charge indicators) and red (e.g., fault indicator). Through the use of a cloud-based application, the EVSE provides the user with a cumulative energy viewing capability. The cloud application accurately displayed charge power and current, but did not correctly display voltage or energy transferred. This was evaluated at both $208 \mathrm{VAC}$ and $240 \mathrm{VAC}$. The energy displayed on two of the pages on the Siemens cloud application did not correlate to each other. One display did increment (i.e., "Usage Tab"), but it was inaccurate, while the other display (i.e., "Home Tab") did not increment.

The Siemens smart grid-capable EVSE successfully charged production plug-in electric vehicles during functional tests (i.e., the Chevy Volt and Nissan Leaf). Grid interrupt tests showed that charging activities resumed after approximately 10 minutes of delay time without manual intervention. 